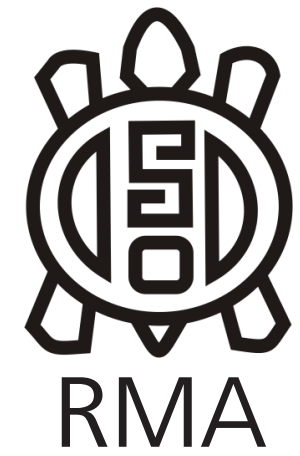

Dossier

Wichí: El mundo

\title{
Morfología botánica wichí: un estudio etnobiológico
}

\author{
Wichi plant morphology: an ethnobiological study
}

María Eugenia Suárez*

\begin{abstract}
*Grupo de Etnobiología del Instituto de Micología y Botánica (UBA-CONICET) y Departamento de Biodiversidad y Biología Experimental, Facultad de Ciencias Exactas y Naturales, Universidad de Buenos Aires. E-mail: eugesuarez78@gmail.com
\end{abstract}

\section{Resumen}

En este artículo estudio la morfología botánica desde la perspectiva de los wichís del Gran Chaco. Además, estudio aquí el léxico de las partes de las plantas desde un marco etnobiológico con fines más amplios, vinculados al entendimiento de los procesos y las motivaciones que están detrás de las clasificaciones vernáculas de la naturaleza. Así pues, intento responder a las siguientes preguntas: ¿cómo describen, entienden y nombran los wichís las partes de las plantas?, ¿cómo es el proceso de asignación de nombres? ¿son criterios morfológicos, funcionales y/o posicionales los que subyacen a lo anterior? En base a datos primarios, describo y analizo 38 términos de partes vegetales, identificando homonimias, partes distintivas de las plantas, criterios y conceptos subyacentes en la partonimia y nomenclatura. Como conclusiones encuentro que: a) no existe un término vernáculo para la categoría "planta", aunque Ihile podría estar adquiriendo esa nueva acepción; b) para especies con gran relevancia cultural existen términos específicos y sufijos para derivar el nombre de los frutos, por lo que el análisis terminológico resulta una vía útil para identificar especies y recursos de importancia local; c) hay una idea de repetición o reiteración en la estructura general de una planta que se refleja en la forma de nombrar a ciertas partes; d) hay criterios morfológicos, funcionales, posicionales y simbólicos detrás de la asignación de nombres de partes; y e) la nomenclatura de las partes de las plantas puede reflejar la pérdida de saberes y/o prácticas sobre especies silvestres.

Palabras clave: Etnobotánica; Interculturalidad; Etnoclasificación; Léxico vernáculo; Meronimia; Partonimia.

\begin{abstract}
In this article I study the plant morphology from the perspective of the Wichi people of the Gran Chaco. I specifically study here the lexicon of plant parts with wider aims in mind, which are related to the comprehension of motivations and processes behind vernacular classifications of nature. Being ethnobiology the frame of the research, I try to answer how Wichi people describe, name and understand plant parts; how is the process of assigning names; and if morphological, functional and/or positional criteria underlie this action. Using primary data, I describe and analyse 38 terms that name plant parts, identifying homonymies, parts that are distinctive of plants, criteria and concepts underlying partonomy and nomenclature. I conclude that: a) there isn't a vernacular term for the category "plant", although Ihile may be acquiring this new meaning; b) for culturally relevant species, there are specific terms and suffixes to derivate the name of fruits, thus the analysis of terms is a useful way to identify species and resources of local importance; c) there is an idea of repetition or reiteration in the general plant structure which is reflected in the form of naming some plant parts; d) there are morphological, functional, positional and symbolic criteria behind the names of plant parts; and e) nomenclature of plant parts can reflect the loss of practices and/or knowledge on some wild species.
\end{abstract}

Keywords: Ethnobotany; Interculturality; Ethnoclassification; Vernacular lexicon; Meronymy; Partonomy.

\section{Introducción}

Este trabajo se centra en el estudio de la morfología botánica desde la perspectiva de los indígenas wichís del Gran Chaco sudamericano. Se trata de un pueblo cazador-recolector, de tradición oral, hoy con alrededor de 60.000 personas, mayormente bilingües wichíespañol, que habitan en el norte argentino y sudeste de
Bolivia (Figura 1), donde parte de los bosques nativos aún persisten, a pesar de los desmontes masivos causados por el modelo productivo extractivista hegemónico (Arenas, 2003; Golluscio y Vidal, 2010; Hansen et al., 2013; Leake, 2010; Palmer, 2005; Montani, 2017; Suárez, 2014). Los wichís, como todo grupo humano, tienen sus propias formas de percibir, nombrar y clasificar los seres vivos de su entorno y los ecosistemas, las cuales cambian a 
través del tiempo a medida que factores socioambientales afectan la experiencia con el entorno y los seres que en él habitan. En esta línea, los wichís construyen su propia "biología", cuyos conceptos, bases y parámetros pueden corresponderse o no con aquellas de la biología académica occidental. La etnobiología, en cuyo marco se desenvuelve este artículo, es la disciplina científica dedicada al estudio de esas otras biologías, donde el foco está puesto en las relaciones entre el grupo humano bajo estudio, los seres vivos de su entorno y el ecosistema en su conjunto, oficiando de interlocutora entre ambas ciencias (Arenas y Martínez, 2012; Ellen, 2018). Dentro de dichas relaciones se incluyen las maneras y procesos vernáculos de concebir, describir y explicar el funcionamiento y la estructura de los seres vivos, así como de clasificarlos, agruparlos en categorías (nombradas o innombradas) y asociarlos.

El estudio de los sistemas clasificatorios vernáculos es un tema central y de sumo interés para la etnobiología, en especial para la rama cognitiva (Berlin, 1992; Ellen, 2018). Asociada intrínsecamente con la antropología cognitiva, podría decirse que el interés común se centra en la búsqueda de principios que subyacen y ordenan las observaciones y los comportamientos en niveles más amplios. Como cualquier otro campo científico, la etnobiología busca patrones en los fenómenos percibidos y desencadenantes ("drivers") que dan cuenta y ayudan a explicar dichos patrones (Blount, 2011; Ellen, 2018; Ross y Hertzov, 2018). En este sentido, una de las preguntas clásicas de la etnobiología es si las clasificaciones asociadas a la naturaleza están basadas en criterios o atributos utilitarios o funcionales, o morfológicos o perceptuales (Brown, 1995; Dwyer, 2005; Hunn, 1982). Hoy se puede afirmar que los criterios subyacentes pueden variar de acuerdo a diversos factores como la edad o el género de la persona consultada, su experiencia o conocimiento específico en un área, su cosmovisión, así como también si se trata de clasificaciones generales u orientadas a propósitos específicos (Ellen, 2006; Kujawska et al., 2017; Medin et al. 1997; Poncet et al., 2015). En la actualidad, algunos estudios de etnobiología cognitiva han ido más allá de describir e interpretar los sistemas clasificatorios y han comenzado a atender el estatus ontológico de las categorías clasificatorias, interesándose así en cómo la gente concibe o conceptualiza a una especie y en qué medida considera que distintas especies comparten ciertos atributos (Ross y Hertzog, 2018). Estas preguntas y abordajes son (o deberían ser) muy relevantes para diversos campos disciplinares, en especial aquellos vinculados a la conservación y el manejo sustentable de recursos y ecosistemas (Ludwig, 2018; Ross y Hertzog, 2018). Esto es así porque el grado en que los humanos nos pensamos a nosotros mismos como seres que compartimos características o atributos con otros seres o entidades condicionan cómo nos relacionamos e interactuamos con ellos; es decir, el estudio de los sistemas clasificatorios permite en parte comprender cómo las diferencias y similitudes crean distancias ontológicas entre humanos y no-humanos, las cuales, a su vez, influyen en cómo los humanos nos posicionamos y actuamos sobre el ecosistema (Descola, 2012; Ross y Hertzog, 2018). Así, la investigación sobre factores subyacentes en la categorización, percepción y razonamiento son cruciales no sólo para las ciencias interesadas en lo cognitivo, sino para campos del saber que a priori -quizás- parecieran desenvolverse lejos de estos temas y no necesitar de esta información (Ludwig, 2018).

En etnobiología son escasos los antecedentes que se dediquen específicamente al estudio detallado de las partes de las plantas. Un estudio destacable al respecto es el de Friedberg (1990), que fue una inspiración para mí en este sentido y que es un claro ejemplo de que estudiar la morfología botánica vernácula es sumamente útil para analizar y comprender la etnoclasificación de las plantas. En relación a la cultura wichí, encontré solo dos antecedentes etnobiológicos concretos que abordan el estudio del léxico y concepciones sobre las partes de las plantas: el de Maranta (1987), quien describe la terminología de los órganos vegetales alimenticios y provee una breve explicación sobre las formas de nombrar y concebir a las partes vegetales, y el trabajo que realicé junto a Rodrigo Montani sobre las Bromeliaceae del Chaco (Suárez y Montani 2010), donde incluimos y analizamos el léxico de las partes de las especies de esta familia botánica. Aunque no enfocadas en la morfología, obras previas de mi autoría en las que estudié la fitonimia y las etiquetas clasificatorias wichí de las plantas según su forma de vida (Suárez, 2010, 2011, 2014), son antecedentes de relevancia para este trabajo y cuyos resultados motivaron el abordaje de este tema específico. Asimismo, la obra clásica de Pastor Arenas (2003), de infaltable consulta en la etnobiología y la etnografía wichís, contiene datos importantes sobre nombres y usos de partes, pero no se dedica al análisis de los nombres, su significado y motivaciones. Desde la antropología, algunos trabajos aportan datos importantes sobre nombres de partes y concepciones asociadas, destacándose los trabajos de Alvarsson (2012) sobre la etnografía 'weenhayek en general y al estudio etnolingüístico de la cultura material wichí de Montani (2017). El artículo de Miguel Ángel de los Ríos (1976), que versa sobre la nomenclatura wichí del cuerpo humano, resulta un antecedente de particular interés, ya que incluye datos e interpretaciones sobre homonimias y polisemias con el mundo vegetal. Trabajos provenientes de diversas disciplinas, diccionarios o léxicos de la lengua wichí fueron fuentes también útiles para este estudio, especialmente desde un punto de vista lingüístico (p. ej., Dell'Arciprete y Braunstein, 2006; Hunt, 1936; Lunt, 2016; Palmer, 2005; Terraza, 2009; Tovar, 1981; Nercesian, 2014; Viñas Urquiza, 1974a, 1974b). Aunque dedicado a la lengua tikuna, un trabajo digno de mención es el de Montes-Rodríguez (2001), 


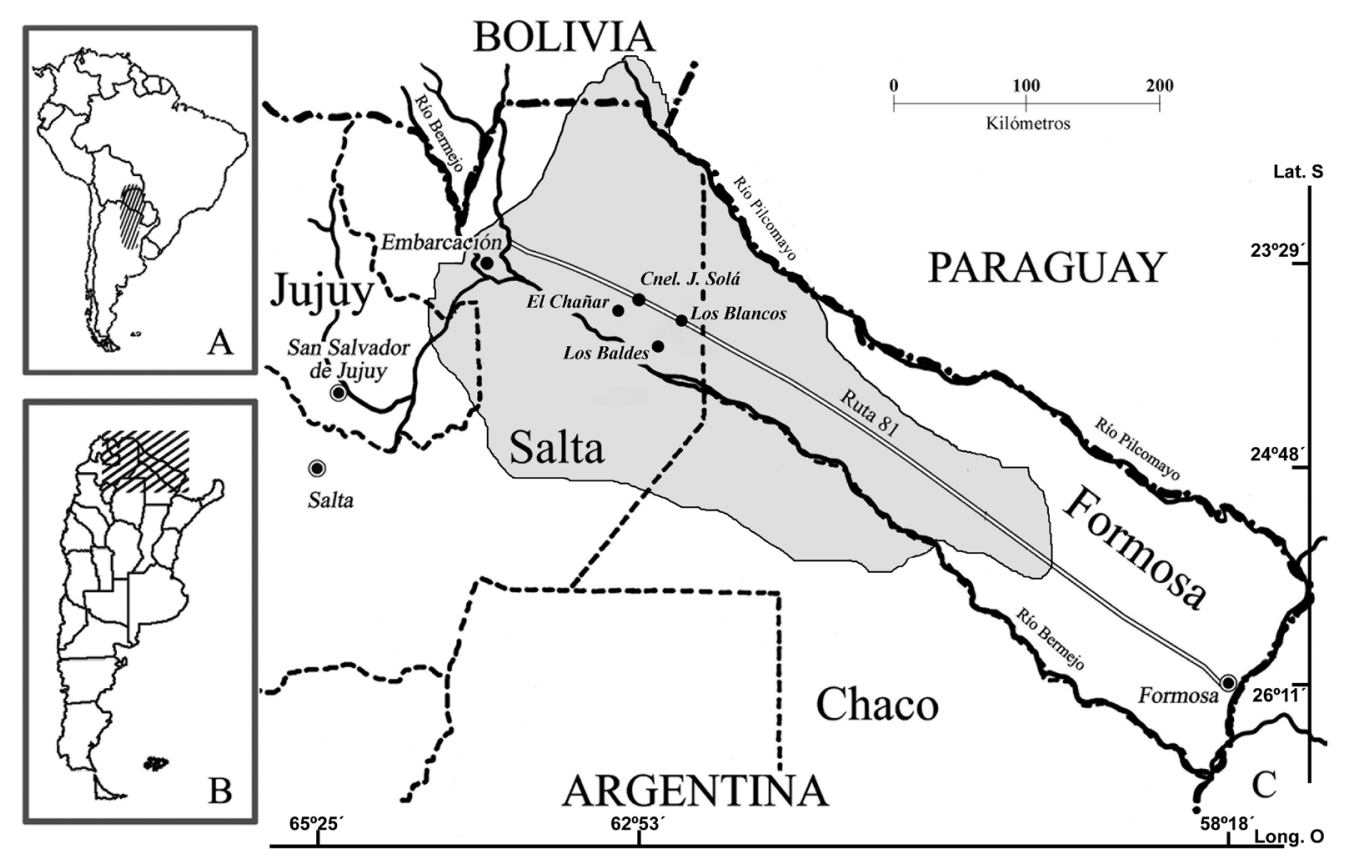

Figura 1. A) El Gran Chaco en Sudamérica; B) El área de estudio en la Argentina; C) El área de estudio con la distribución actual aproximada del pueblo wichí (sombreado) y las principales localidades donde se realizó el trabajo de campo.

Figure 1. A) The Gran Chaco in South America; B) The study area in Argentina; C) Map of the study area with the current approximated distribution of the Wichi people (in grey) and the main localities where fieldwork was carried out.

que analiza los nombres de las partes vegetales desde una perspectiva etnolingüística. Cabe mencionar que es muy usual que obras lingüísticas o antropológicas como las recién mencionadas en general traduzcan y/o definan los términos botánicos wichís con un término en español cuya equivalencia no necesariamente es tan directa, contundente y/o unívoca como suele presentarse. Y como en toda traducción entre lenguas, es el significado de fondo, no solo el término, lo que importa para una adecuada interlocución. En este sentido, estudios etnobiológicos como el que aquí propongo pueden aportar particularmente a la educación intercultural bilingüe (EIB) formal y noformal, que en el país y la región, aún necesita reflexión y mejoras sustanciales (Schmidt, 2011; Schmidt y Hecht, 2015; Wallis, 2010).

En base a lo antedicho, el propósito general de este artículo es aportar al conocimiento y comprensión de la etnobiología wichí, en particular de aspectos cognitivos y etnoclasificatorios. Dado que una de las formas posibles de adentrarse a los criterios que están detrás de las clasificaciones vernáculas es la lengua, que es un mecanismo conceptualización y comunicación (Berlin, 1992; Cardona, 1994; Luque Durán, 2001), intentaré en este artículo aportar a lo anterior analizando la terminología vinculada a las partes de las plantas en la botánica wichí. El problema central de este artículo es entonces cómo perciben y nombran la morfología de plantas los wichís y cuáles son los criterios subyacentes a dicha nomenclatura. Las preguntas que guían el trabajo son ¿cómo los wichís describen, entienden y nombran las partes de las plantas?, ¿cómo es el proceso de asignación de nombres de las partes vegetales? ¿son criterios morfológicos, funcionales y/o posicionales los que subyacen a lo anterior? Me propongo, por ende: a) compendiar el léxico wichí vinculado a las partes de las plantas y proveer una traducción acorde a las concepciones vernáculas; b) analizar el léxico en el contexto de la propia cultura, examinando cómo se concibe la morfología botánica y cómo se asignan nombres las partes; y c) identificar criterios subyacentes en la nomenclatura registrada, analizando posibles transferencias metafóricas y/o metonímicas desde otros campos semánticos.

\section{Consideraciones metodológicas}

Trabajé con las técnicas de obtención y análisis de información cualitativas habituales en etnobiología, en mis investigaciones y en las de mi grupo de trabajo, que combinan trabajo de campo, laboratorio y gabinete (Arenas y Martínez, 2012; Suárez, 2014). Con la etnografía como base fuerte en la investigación etnobotánica, obtuve los datos primarios a partir de entrevistas abiertas, recorridos por el entorno, recolección de material de herbario de referencia y observación participante. Realicé campañas desde 2005 a la fecha; entre 2013 y 2017 profundicé particularmente este tema. Trabajé sobre este tema con 67 personas adultas (36 mujeres y 31 varones) 
que habitan en distintas comunidades wichís del este de la provincia argentina de Salta, especialmente en las de la zona de influencia de los pueblos Coronel Juan Solá y Los Blancos, y las aldeas wichís de Los Baldes y El Chañar (Figura 1). Para identificar y ahondar en la partonimia (o meronimia), nomenclatura y morfología general de las plantas, durante las entrevistas se usaron en ocasiones dibujos, esquemas y fotos (similares a los que se observan en las Figuras 2 y 3) numerosos y variados, además de material vegetal fresco. Las plantas identificadas en el laboratorio fueron depositadas en distintos herbarios del país (CTES, BA, SI) ${ }^{1}$ para que se conserven como material de referencia. Para la identificación, la información etnobotánica y la exsiccata de las plantas estudiadas remito a Suárez $(2014,2019)$. En este trabajo empleo el alfabeto usado por Lunt (2016) en su diccionario, con las excepciones de que incluyo la $\ddot{e}$ y uso jw en lugar de $f w$, porque considero que esto es más acertado para las variantes regionales. El alfabeto usado es entonces: $a$, $\ddot{a}, c h, c h h, c h^{\prime}, e, \ddot{e}, h, i, j, j w, k, k h, k^{\prime}, k w, k w^{\prime}, I, I^{\prime}, I h$, $m, m h, m^{\prime}, n, n h, o, p, p h, p^{\prime}, s, t, t h, t^{\prime}, t s, t s h, t s^{\prime}, u$, $w, w h, w^{\prime} . y, y h, y^{\prime}, '$

\section{Las plantas como entidad}

Antes de hablar de las partes de las plantas debo referirme brevemente a la planta entera. No pretendo ahondar aquí en las etiquetas clasificatorias de las distintas clases de plantas, tema que continúo estudiando y sobre el que he publicado algunos resultados (Suárez, 2010, 2011, 2014; Suárez y Montani, 2010), pero cabe mencionar que hasta el momento no puedo afirmar que exista en wichí un término equiparable a "planta" en el sentido que le damos en español y/o en la biología académica, aún cuando los wichís sí conciban a las especies vegetales como entidades relacionadas. De hecho, durante las entrevistas los wichís usaron ocasionalmente el término "planta", en español, dentro de una frase en lengua wichí, para aludir a ese concepto. Esto mismo parece haber registrado Terraza (2009: 97). En realidad, lo habitual para referirse a conjuntos de plantas en general es que empleen términos que son etiquetas del nivel "formas de vida", como haläy (árboles-arbustos) o haläywatsan ("yuyos"; lit. palos-verdes; hierbas, subarbustos) (Suárez, 2010, 2011, 2014). Todo esto no es de extrañar, pues es sabido que muchas lenguas del mundo carecen de un término para etiquetar lo que sería la categoría de "reino" o "iniciador único" y es usual que sí se utilicen etiquetas de nivel de "forma de vida" o "géneros" (Berlin, 1992; Luque Durán, 2001, pp. 268 y ss.; Ross y Hertzog, 2018).

Más allá de eso, en wichí existen dos términos que se relacionan con el concepto "planta". Uno de ellos es

\footnotetext{
${ }^{1}$ Los herbarios se identifican a nivel internacional con acrónimos específicos. CTES: Instituto de Botánica del Nordeste (Corrientes); SI: Instituto de Botánica "Darwinion" (San Isidro); BA: Museo Argentino de Ciencias Naturales "Bernardino Rivadavia" (Buenos Aires).
}

käs (pl. käs/hais), que frecuentemente es traducido al español con esa palabra, tanto por los wichís durante las conversaciones como por académicos en sus obras. Este término, en sentido estricto, significa 'planta cultivada' según mis registros y los de otros autores (p. ej., Lunt, 2016; Montani, 2017). Las plantas silvestres, que crecen espontáneamente, no son clasificadas como käs. Al menos no son wichi-käs, 'planta cultivada de la gente'. En todo caso, son cultivadas por seres o espíritus del monte que son sus "dueños" o son "dueños" del ámbito donde crecen (Suárez, 2012; Suárez y Montani, 2010). El uso del término käs en el habla cotidiana ocurre normalmente cuando justamente lo que se quiere remarcar es la relación entre la planta y su "cultivador", su "dueño", y no para referirse a las plantas en general. En otras palabras, solo las especies vegetales que son cultivadas o cuidadas son käs. A nivel lingüístico, Montani (2017: 489ss) explica que el término -käs es también un "clasificador posesivo" que se aplica a "nombres independientes" o inalienables para indicar específicamente que la entidad en cuestión se trata de una "planta cultivada", lo cual está en línea con mis resultados. Por otra parte, Alvarsson (2012: 41) traduce como "planta" al término käs (en su grafía qàs), pero emplea el término 'nooqàswet (su grafía) para referirse al huerto y a la actividad horticultura en sí. En la grafía del presente trabajo, dicho término sería nokäs-wet, que podemos traducir como 'lugar/casa/morada de la planta cultivada de alguien', el huerto, acepción registrada por mí y por otros autores (p. ej., Arenas, 2003, p. 320; Lunt, 2016, p. 48; Maranta, 1987, p. 190; Montani, 2017, p. 203). Algo similar ocurre en obras lingüísticas, como en la de Nercesian (2014), que a veces traduce käs como 'planta' (p. 129), pero al profundizar sobre el término lo presenta como "planta no silvestre cuidada por alguien" (2014, p. 161). Existe consenso, entonces, en que el término refiere específicamente a 'planta cultivada'. Mi conclusión sobre su traducción ocasional al español como "planta" es que el propio término en español remite tanto a un vegetal que "se planta", se cultiva, como a las especies vegetales en general, pero käs no tiene nunca esta última acepción.

El otro término que algunos entrevistados han empleado ocasionalmente para referirse a planta como el conjunto de todas las especies vegetales es Ihile (pl. Ihiley). Según mis datos y la bibliografía, el término Ihile es un sustantivo dependiente que significa primariamente 'hueso' (de humanos y otros animales) y 'tallo' (de plantas) (cf. p. ej., Lunt, 2016; Tovar, 1981; Viñas Urquiza, 1974b). En botánica wichí, Ihile refiere también a toda parte con semejanza morfológica y/o funcional a tallos o huesos (p. ej., las nervaduras de hojas o pecíolos también son llamados Ihiley de las hojas) (Tabla 1). Pero más allá de eso, el término Ihile se emplea para hacer referencia a la planta entera. Dependiendo del contexto de la conversación, el nombre compuesto [nombre específico de la planta + Ihile] puede significar tallo de esa planta o indicar que se está hablando de esa planta entera, de 
toda la planta. Por ejemplo: la enredadera denominada en el español local como "mandioca del monte" (Marsdenia castillonii) se denomina newok en wichí; y el compuesto newok-Ihile (o su pl., newok-Ihiley) puede significar 'tallo/ rama de newok' o 'planta newok', refiriéndose en este último caso a la totalidad de un ejemplar o individuo de esa etnoespecie, usualmente para remarcar que está hablando de toda la planta y no de una parte (p. ej., del fruto). Incluso algunas expresiones referidas al cuerpo humano usan Ihile para referirse al cuerpo entero de un humano o animal, como la registrada por Viñas Urquiza (1974a, p. 100): tik iwahatlhi häp Ihiley talhamë häp lhetek 'no movía su cuerpo, solo su cabeza' (su grafía, mi resaltado). Conceptualmente, considero entonces que el término /hile remite no sólo al hueso o tallo, es decir, cada pieza o parte del esqueleto, sino también a la estructura o armazón completo de un ser (humano, animal o planta), y de ahí que se emplee también para hacer alusión a la planta entera. Mi conclusión sobre la traducción ocasional de Ihile como 'planta' es que ésta se realiza en el habla sólo ante la necesidad, por ser el término más cercano a la concepción de plantas como el conjunto de las especies vegetales; o quizás el término está en proceso de adquirir esta nueva acepción por el devenir de los cambios socioculturales, en particular al encontrarse las nuevas generaciones dentro del sistema educativo formal.

\section{Las partes de las plantas y sus nombres}

En la Tabla 1 se presentan los nombres recopilados de las partes de las plantas en wichí, sus correspondencias para la botánica académica y algunas aclaraciones que tienden a precisar la traducción. Asimismo, se incluyen otras acepciones de los términos, de otros campos semánticos (cuerpo humano y/o de otros animales, conceptos abstractos) que fueron registradas en el campo y corroboradas en su mayoría con la bibliografía consultada,
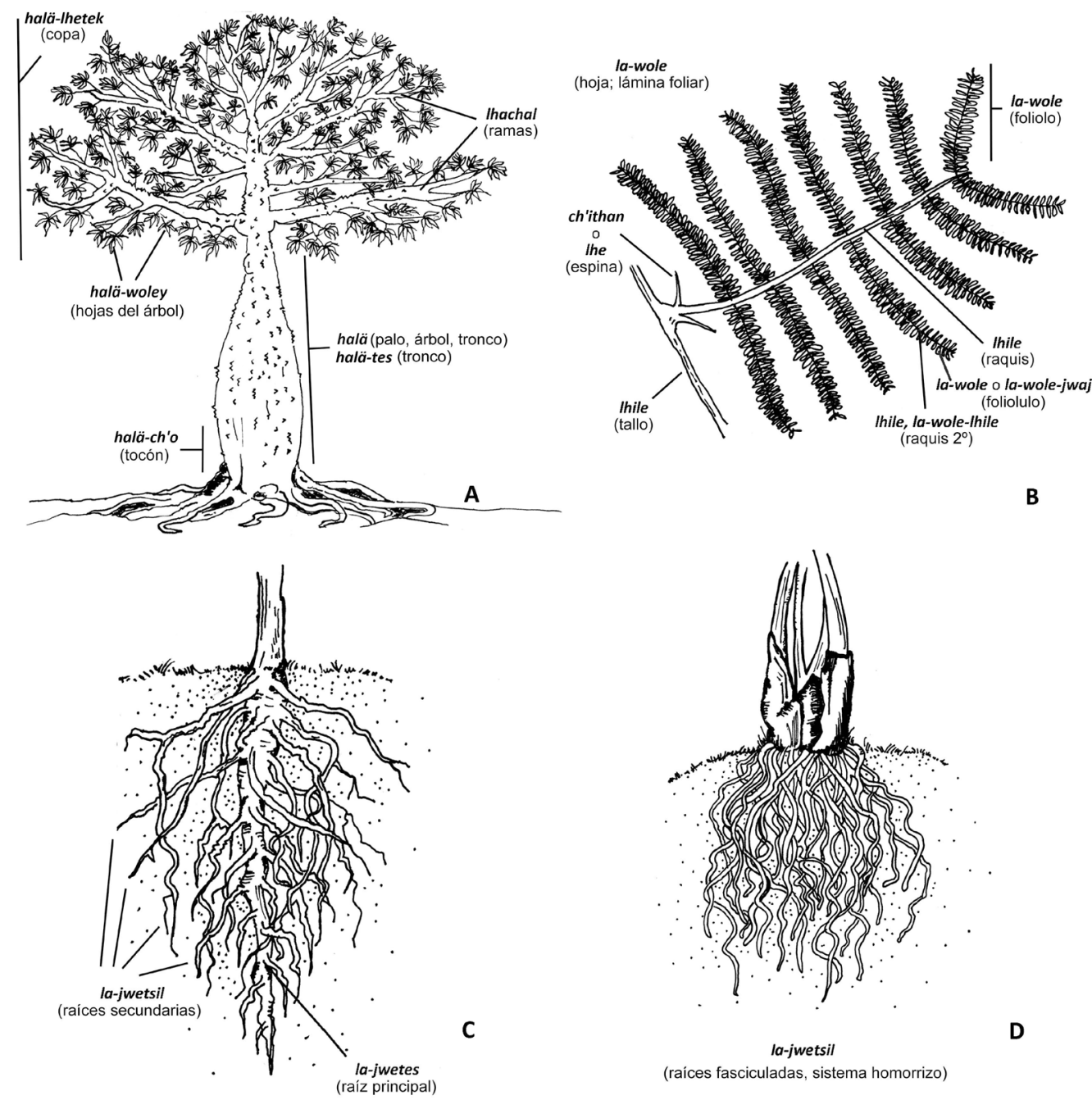

Figura 2. Dibujos y nombres wichís de algunas partes de las plantas. A) Árbol con los nombres de algunas partes de su morfología general. B) Nombres de partes de una hoja bipinnada. C) Sistema radicular alorrizo. D) Sistema radicular homorrizo.

Figure 2. Drawings and Wichi names of some plant parts. A) Tree with names of some parts of its general morphology. B) Names of the parts of a bipinnate leaf. C) Tap root system. D) Fibrous root system. 
Tabla 1. Nombres wichí de partes vegetales, sus correspondencias para la botánica académica, aclaraciones detalladas, otras acepciones de los términos registrados y criterios subyacentes identificados para los términos polisémicos. Criterios: FUN funcional, MOR morfológico, POS posicional.

Table 1. Wichi names of plant parts, their correspondences for academic botany, pertinent detailed clarifications, other meanings of the recorded names and underlying identified criteria for polysemic names. Criteria: FUN functional, MOR morphological, POS positional.

\begin{tabular}{|c|c|c|c|c|}
\hline $\begin{array}{l}\text { Nombre de parte / } \\
\text { Figura }\end{array}$ & $\begin{array}{l}\text { Correspondencia } \\
\text { botánica }\end{array}$ & Aclaraciones & Otras acepciones & Criterio \\
\hline $\begin{array}{l}\text { halä }(\mathrm{s}) \text {, haläy }(\mathrm{pl}) \\
\text { FIG. } 2 \mathrm{~A}\end{array}$ & $\begin{array}{l}\text { Madera; Tronco (palo, } \\
\text { tallo leñoso) }\end{array}$ & $\begin{array}{l}\text { Se emplea el término para referir a todo un árbol/arbusto o bien } \\
\text { específicamente al tronco, al tallo principal, o a la madera. } \\
\text { Además, es una etiqueta clasificatoria dentro de la que se agrupa } \\
\text { a árboles y arbustos (Suárez, 2010, 2014). }\end{array}$ & & \\
\hline $\begin{array}{l}\text { Ihacha (s), Ihachal } \\
\text { (pl) } \\
\text { FIG. 2A }\end{array}$ & Rama; Ramificaciones & $\begin{array}{l}\text { Se usa para las ramificaciones caulinares principalmente, pero } \\
\text { puede aplicarse también a ramificaciones de inflorescencias que } \\
\text { asemejan las ramas de un árbol, como las de Bromelia hieronymi } \\
\text { (cháguar, chitsaj). Probablemente, el término Ihacha provenga } \\
\text { de Iha, fruto, y cha, instrumento/herramienta. }\end{array}$ & & \\
\hline $\begin{array}{l}\text { Ihich'u (s), Ihich'ul } \\
\text { (pl) }\end{array}$ & $\begin{array}{l}\text { Duramen; Médula del } \\
\text { tallo; Parte más interna } \\
\text { de algunos frutos o } \\
\text { semillas }\end{array}$ & $\begin{array}{l}\text { En el caso de especies leñosas, según la especie y su morfología, } \\
\text { se refiere al duramen o a la médula. Por ejemplo, en el caso del } \\
\text { 'cardón' (istak, Stetsonia coryne), se refiere a la médula del tallo, } \\
\text { esponjosa y reseca cuando madura. En el caso de las maderas } \\
\text { sólidas, es el duramen. } \\
\text { Se aplica además a la parte central o más internas de algunas } \\
\text { semillas, como las de quebracho blanco, Aspidosperma } \\
\text { quebracho blanco, que son aladas: Ihich'u es la parte de la } \\
\text { semilla sin el ala. En el caso de ciertos frutos, como las drupas, } \\
\text { suele llamarse Ihoy-lhich'u (huevo de la semilla) a la semilla, ya } \\
\text { que se considera que el endocarpo leñoso es su "cáscara". }\end{array}$ & -Huevo & POS \\
\hline chowej & $\begin{array}{l}\text { Duramen; Médula del } \\
\text { tallo }\end{array}$ & $\begin{array}{l}\text { Ídem comentario que para Ihich'u. Este término también se } \\
\text { aplica a la parte interna o central de la roseta basal de las plantas } \\
\text { arrosetadas, como las Bromeliaceae terrestres, que corresponde } \\
\text { en ese caso a las vainas foliares internas, jóvenes (ver Suárez \& } \\
\text { Montani 2010). }\end{array}$ & $\begin{array}{l}\text {-Medio/centro } \\
\text {-Centro vital (de una persona) } \\
\text {-Parte situada en el medio del } \\
\text { pecho del cuerpo humano, } \\
\text { internamente, en la zona del } \\
\text { esternón. }\end{array}$ & POS \\
\hline chulak & $\begin{array}{l}\text { Duramen; Médula del } \\
\text { tallo }\end{array}$ & $\begin{array}{l}\text { Ídem comentario que para Ihich'u. Este término no es usado en } \\
\text { la zona de estudio, pero sí lo conocen como sinónimo. }\end{array}$ & $\begin{array}{l}\text {-Medio/centro/núcleo } \\
\text {-Cerebro/parte adentro del cráneo }\end{array}$ & POS \\
\hline t'otle & Duramen & $\begin{array}{l}\text { Posiblemente tomado del español local, que le llama 'corazón' al } \\
\text { duramen del palo. Muchos entrevistados sostuvieron que es } \\
\text { poco frecuente el uso, que se dice así en otros lugares/regiones. }\end{array}$ & $\begin{array}{l}\text {-Corazón (humanos y otros } \\
\text { animales) }\end{array}$ & POS \\
\hline $\begin{array}{l}c h^{\prime} o(s), c h^{\prime} o s(\mathrm{pl}) \\
\text { FIG. } 2 A\end{array}$ & Tocón & $\begin{array}{l}\text { La expresión es halä-ch'o, que alude a la parte de abajo del palo, } \\
\text { del vástago. }\end{array}$ & -Abajo & POS \\
\hline $\begin{array}{l}\text { Ihetek (s), Ihetey } \\
\text { (pl) } \\
\text { FIG. 2A }\end{array}$ & $\begin{array}{l}\text { Copa (de árbol o } \\
\text { arbusto); Roseta basal }\end{array}$ & $\begin{array}{l}\text { Halä-Ihetek (copa del árbol). [nombre de la planta]-Ihetek (roseta } \\
\text { basal, p.ej. de Bromelia spp.) }\end{array}$ & $\begin{array}{l}\text {-Cabeza (humanos y otros } \\
\text { animales) }\end{array}$ & $\begin{array}{l}\text { MOR } \\
\text { ¿POS? }\end{array}$ \\
\hline $\begin{array}{l}t^{\prime a ̈ j j}(\mathrm{~s}), t^{\prime} \ddot{a j e s}(\mathrm{pl}) \\
\text { FIG. 3C, 3D, 3E }\end{array}$ & $\begin{array}{l}\text { Cáscara; Corteza; } \\
\text { Tegumento seminal; } \\
\text { Pericarpo (o alguna } \\
\text { parte específica); Hoja } \\
\text { (escamosa) }\end{array}$ & $\begin{array}{l}\text { Según el caso alude a distintas partes, con distintas } \\
\text { construcciones lingüísticas. Así, la-wole-t'äj, epidermis foliares; } \\
\text { lhawo-t'äj, brácteas florales; lha-t'oj, cáscara del fruto (según el } \\
\text { caso puede ser epi+mesocarpo, o solo epicarpo, etc.); lho-t'äj, } \\
\text { tegumento seminal o endocarpo leñoso (en drupas); halo-t'äj, } \\
\text { corteza de árbol/arbusto; Ihile-t'äj, corteza del tallo; jwetes-t'äj, } \\
\text { corteza de la raíz; le-ch'u-t'äj, hojas del estolón. }\end{array}$ & -Piel, cuero & $\begin{array}{l}\text { MOR } \\
\text { POS } \\
\text { FUN }\end{array}$ \\
\hline $\begin{array}{l}\text { Ihile (s), Ihiley (pl) } \\
\text { FIG. 2B, 3A }\end{array}$ & $\begin{array}{l}\text { Tallo; Nervadura; Planta } \\
\text { entera; Escapo; Raquis; } \\
\text { Ramificación }\end{array}$ & $\begin{array}{l}\text { El término siempre se emplea para remitir a la idea de eje, hueso } \\
\text { o esqueleto. Se usa en distintas construcciones lingüísticas para } \\
\text { aludir a una u otra parte específica. Así, Ihiley son los tallos de la } \\
\text { planta en general, [nombre de la planta]-Ihiley; la-wole-Ihiley, } \\
\text { 'los huesos/tallos/ejes de la hoja', son las nervaduras de una } \\
\text { hoja; la-wole-Ihile, 'el hueso/tallo/eje de la hoja', el raquis de una } \\
\text { hoja compuesta; Ihawo-Ihiley, 'los huesos/tallos/ejes de la flor', } \\
\text { en plural, son el eje y las ramificaciones de una inflorescencia } \\
\text { racimosa; Ihawo-Ihile, 'el hueso/tallo/eje de la flor', en singular, } \\
\text { un escapo floral. Además, el término se emplea para referir a } \\
\text { una planta entera, por ejemplo, hataj-lhile, 'planta de hataj } \\
\text { (cebil, Anadenanthera colubrina)'. }\end{array}$ & $\begin{array}{l}\text {-Hueso } \\
\text {-Eje } \\
\text {-Espina de pez }\end{array}$ & $\begin{array}{l}\text { MOR } \\
\text { FUN } \\
\text { POS }\end{array}$ \\
\hline $\begin{array}{l}\text { Iho }(\mathrm{s}) \text {, Ihoy (pl) } \\
\text { FIG. 3D, 3E }\end{array}$ & Semilla & $\begin{array}{l}\text { En ciertos casos, como algunas drupas, al endocarpo leñoso se lo } \\
\text { considera parte de la semilla, su cáscara. }\end{array}$ & -Pene & FUN \\
\hline $\begin{array}{l}\text { Iha (s), Ihay (pl) } \\
\text { FIG. 3C, 3D, 3E }\end{array}$ & $\begin{array}{l}\text { Fruto; Tubérculo; Bulbo; } \\
\text { Raíz }\end{array}$ & $\begin{array}{l}\text { La acepción primaria y la traducción principal al español y para la } \\
\text { botánica académica es 'fruto'. Sin embargo, en términos } \\
\text { botánicos estrictos, según la especie, otras partes (distintas al } \\
\text { fruto) de una planta pueden ser llamadas y concebidas como lha. } \\
\text { Éstas siempre son conspicuas, prominentes, engrosadas respecto } \\
\text { a la misma parte de otras especies, y son usualmente partes } \\
\text { útiles importantes culturalmente, ya sea para fines alimenticios, } \\
\text { mágicos, medicinales, hidratantes, etc. De ahí que raíces } \\
\text { engrosadas, tubérculos y bulbos sean considerados Ihay. }\end{array}$ & & \\
\hline
\end{tabular}




\begin{tabular}{|c|c|c|c|c|}
\hline $\begin{array}{l}\text { Ihawo (s), Ihawol } \\
\text { (pl) } \\
\text { FIG. 3A, 3B, 3C, 3E }\end{array}$ & $\begin{array}{l}\text { Flor; Pelos seminales; } \\
\text { Pétalo; Inflorescencia; } \\
\text { Infrutescencia; Espata + } \\
\text { espádice }\end{array}$ & $\begin{array}{l}\text { La acepción primaria y la traducción principal al español y para la } \\
\text { botánica académica es 'flor'. Sin embargo, en términos botánicos } \\
\text { estrictos, según la especie, otras partes (distintas a la flor) de una } \\
\text { planta pueden ser llamadas y concebidas como Ihawo. Así, en el } \\
\text { caso de especies con flores inconspicuas o muy pequeñas se } \\
\text { concibe como Ihawo a toda la inflorescencia, p.ej. en el caso de } \\
\text { las Asteraceae o las 'totoras' (jwin'a, Typha domingensis). Se } \\
\text { llama Ihawo además al conjunto de pelos seminales de especies } \\
\text { de Apocynaceae asclepiadoideas (p.ej. Marsdenia castillonii) y en } \\
\text { ocasiones a los del 'yuchán' (tsemlhäkw, Ceiba chodatii). En el } \\
\text { caso de Araceae (p.ej. Synandrospadix vermitoxicus) se concibe } \\
\text { como Ihawo al conjunto de espata + espádice. }\end{array}$ & & \\
\hline $\begin{array}{l}\text { jwetes (s), jwetsil } \\
\text { (pl) } \\
\text { FIG. 2C, 2D }\end{array}$ & Raíz & $\begin{array}{l}\text { Además del uso normal de singular y plural para remitir a una o } \\
\text { más raíces, respectivamente, en general se emplea en singular } \\
\text { para referirse a raíces principales y/o engrosadas (en el español } \\
\text { local a veces llamadas raíces macho) de sistemas radiculares } \\
\text { alorrizos, y en plural para referirse a las más delgadas en el } \\
\text { alorrizo (en el español local a veces llamadas raíces hembra) o al } \\
\text { conjunto de raíces de sistemas homorrizos. }\end{array}$ & & \\
\hline $\begin{array}{l}\text { wole }(\mathrm{s}) \text {, woley }(\mathrm{pl}) \\
\text { FIG. } 2 \mathrm{~A}, 2 \mathrm{~B}, 3 \mathrm{~B}\end{array}$ & $\begin{array}{l}\text { Hoja; Lámina foliar; } \\
\text { Foliolo; Foliolulo; } \\
\text { Fronde; Cladodio; } \\
\text { Bráctea; Pétalo o tépalo }\end{array}$ & $\begin{array}{l}\text { Se aplica a: a) hojas simples y sésiles; b) hojas simples pecioladas, } \\
\text { incluyendo el pecíolo, al cual además se lo puede llamar la-wole- } \\
t^{\prime} a k, \text { 'manija de la hoja'; c) hojas compuestas, igual que el caso } \\
\text { anterior en relación al pecíolo y en cuanto a la lámina, se le dice } \\
\text { wole tanto a toda la lámina como a cada foliolo y foliolulo. En } \\
\text { general cuando foliolos o foliolulos son muy pequeños la gente } \\
\text { sostiene que no lleva nombre, pero que se puede decir la-wole o } \\
\text { la-wole-jwaj (pequeña hoja, hojita); d) frondes de helechos, ídem } \\
\text { puntos anteriores; e) cladodios (registrado para Opuntia spp.); f) } \\
\text { brácteas de inflorescencias o de flores (p.ej. Ihawo-woley, 'hojas } \\
\text { de la flor', brácteas de la base del escapo de Bromelia serra), } \\
\text { siempre que se asemejen morfológicamente a otras hojas; g) } \\
\text { pétalos, ocasionalmente se emplea, cuando éstos son } \\
\text { conspicuos, no muy pequeños, a los que se les llama Ihawo- } \\
\text { woley, 'hojas de la flor' (en general simplemente son parte de la } \\
\text { flor, sin llevar nombre específico). }\end{array}$ & $\begin{array}{l}\text {-Pelo } \\
\text {-Pluma }\end{array}$ & $\begin{array}{l}\text { MOR } \\
\text { ¿POS? }\end{array}$ \\
\hline $\begin{array}{l}\text { t'isan (s), t'isanis } \\
\text { (pl) } \\
\text { FIG. 3C, 3D }\end{array}$ & $\begin{array}{l}\text { Albura; Parte interna de } \\
\text { distintas partes (frutos, } \\
\text { tubérculos, bulbos, } \\
\text { rosetas basales, } \\
\text { cogollos) }\end{array}$ & & $\begin{array}{l}\text {-Carne } \\
\text {-Cuerpo } \\
\text {-Relleno }\end{array}$ & $\begin{array}{l}\text { MOR } \\
\text { FUN } \\
\text { POS }\end{array}$ \\
\hline $\begin{array}{l}\text { tes (s), tetsel (pl) } \\
\text { FIG. } 3 \mathrm{~F}\end{array}$ & $\begin{array}{l}\text { Inicio/base de distintas } \\
\text { partes (hojas, vástago, } \\
\text { roseta basal, cogollo); } \\
\text { Parte del tallo principal } \\
\text { entre la raíz y las ramas } \\
\text { (en cualquier tipo de } \\
\text { planta, leñosas o no) }\end{array}$ & $\begin{array}{l}\text { La primera acepción es general y empleada por todos los } \\
\text { entrevistados. Al referirse a la base de una parte se la denomina } \\
\text { así, con la construcción lingüística apropiada (p.ej. la-wole-tes, } \\
\text { 'base/inicio/origen de la hoja', aplicada a la base foliar, donde } \\
\text { empieza, sea peciolada o sésil, con o sin vaina). Se aplica } \\
\text { también, además, para referir al tronco de un árbol, al tallo } \\
\text { principal, desde el suelo hasta las ramas. }\end{array}$ & $\begin{array}{l}\text {-Origen } \\
\text {-Inicio, principio }\end{array}$ & $\begin{array}{l}\text { POS } \\
\text { ¿FUN? }\end{array}$ \\
\hline pes (s), pesey (pl) & $\begin{array}{l}\text { Punta/extremo distal de } \\
\text { distintas partes; Pétalos, } \\
\text { tépalos }\end{array}$ & $\begin{array}{l}\text { El término se usa en general para referir a los extremos distales } \\
\text { de las ramas frondosas de una planta y/o las ramas nuevas en } \\
\text { crecimiento (en primavera-verano), en general incluyendo hasta } \\
\text { 4-5 hojas. Para ello se usa la construcción [nombre de la planta]- } \\
\text { pes/pesey, en general en plural. Sin embargo, también se usa } \\
\text { para referir específicamente a la punta de otras partes, como } \\
\text { puede ser una hoja (p.ej. la-wole-pes, 'punta/final de la hoja', } \\
\text { refiriendo a la punta de una hoja o lámina foliar). Además, para } \\
\text { algunas especies se usa la construcción Ihawo-pes/pesey, } \\
\text { 'punta/final de la flor', aludiendo a los pétalos. }\end{array}$ & $\begin{array}{l}\text {-Punta } \\
\text {-Extremo distal } \\
\text {-Final }\end{array}$ & $\begin{array}{l}\text { POS } \\
\text { ¿FUN? }\end{array}$ \\
\hline $\begin{array}{l}t^{\prime} i(\mathrm{~s}),\left[{ }^{\prime} t^{\prime} i l ?{ }^{\prime} t^{\prime} i l i s ?\right. \\
(\mathrm{pl})]\end{array}$ & $\begin{array}{l}\text { Savia; Látex; Resina; Jugo } \\
\text { (de frutas) }\end{array}$ & $\begin{array}{l}\text { El término se aplica a cualquier exudado o líquido proveniente } \\
\text { de las plantas. Se usa habitualmente para savia y látex, pero es } \\
\text { poco frecuente su uso para referirse a resinas. Es un término que } \\
\text { suele usarse como sinónimo de Ihits'i, pero si una misma persona } \\
\text { usa ambos, } t^{\prime} i \text { se aplica en caso de exudados relativamente más } \\
\text { líquidos (incluso a los exudados que caen de las copas de los } \\
\text { árboles y que suelen corresponden al líquido que emanan ciertos } \\
\text { artrópodos que se alimentan de su savia) y lhits'i a los más } \\
\text { sólidos (resinas, mucílagos). Lunt (2016: } 94 \text { ) registra esas dos } \\
\text { formas para el plural del término. }\end{array}$ & $\begin{array}{l}\text {-Líquido (en general) } \\
\text {-Rocío } \\
\text {-Jugo } \\
\text {-Pus, secreción, lágrimas } \\
\text { (humanos, animales) }\end{array}$ & MOR \\
\hline Ihits'i & $\begin{array}{l}\text { Resina; Mucílago; Látex; } \\
\text { Savia }\end{array}$ & $\begin{array}{l}\text { Ver comentario para t'i. Aquí, a la inversa de lo que ocurre con } \\
t^{\prime} i \text {, se emplea el término para cualquier exudado de las plantas, } \\
\text { pero se usa mayormente para referirse a resinas, látex y } \\
\text { mucílagos. A las cochinillas que suelen habitar en especies del } \\
\text { género Opuntia se las denomina (y concibe) también Ihits'i. }\end{array}$ & & \\
\hline $\begin{array}{l}\text { mokw (s), mokwoy } \\
\text { (pl?) }\end{array}$ & Polen & $\begin{array}{l}\text { Lunt (2016: 62), que anota mok en singular para polvo/pólvora, } \\
\text { da mhoy. }\end{array}$ & $\begin{array}{l}\text {-Polvo } \\
\text {-Ceniza } \\
\text {-Harina } \\
\text {-Pólvora } \\
\text {-Gleba seca (hongos) }\end{array}$ & MOR \\
\hline $\begin{array}{l}\text { Ihe (s), Ihey (pl) } \\
\text { FIG. 2B }\end{array}$ & Espina; Aguijón & $\begin{array}{l}\text { En general usado para espinas cortas. No todos emplean el } \\
\text { término, algunos usan 'itan/ch'ithan y explican que varía por } \\
\text { dialecto. }\end{array}$ & $\begin{array}{l}\text {-Espina de pez (algunas) } \\
\text {-Clítoris }\end{array}$ & $\begin{array}{l}\text { MOR } \\
\text { ¿FUN? }\end{array}$ \\
\hline $\begin{array}{l}\text { 'itan/ch'ithan (s), } \\
\text { 'itanil/ch'ithanil (pl) } \\
\text { FIG. 2B }\end{array}$ & Espina; Aguijón & $\begin{array}{l}\text { No todos emplean el término, algunos usan Ihe y explican que } \\
\text { varía por dialecto. }\end{array}$ & & \\
\hline
\end{tabular}




\begin{tabular}{|c|c|c|c|c|}
\hline tsote $(\mathrm{s})$, tsotey $(\mathrm{pl})$ & Aguijón; Espina & $\begin{array}{l}\text { Cuando aplicado a espina, es para espinas cortas por lo general. } \\
\text { Sólo algunos entrevistados lo emplean. }\end{array}$ & $\begin{array}{l}\text {-Diente (humanos y otros } \\
\text { animales) }\end{array}$ & $\begin{array}{l}\text { MOR } \\
\text { ¿FUN? }\end{array}$ \\
\hline $\begin{array}{l}j w o(\mathrm{~s}), j w o l(\mathrm{pl}) \\
\text { FIG. 3B }\end{array}$ & Gloquidio, jana & & & \\
\hline kwe (s), kweyey (pl) & Zarcillo; Ramas & $\begin{array}{l}\text { Se registró el uso del término para referirse a ramas en el caso } \\
\text { de algunas pocas especies, como Jatropha spp. o algunos cactus } \\
\text { arborescentes, solo por pocos entrevistados. }\end{array}$ & $\begin{array}{l}\text {-Brazo (humanos y otros } \\
\text { animales), o brazo + manos, o } \\
\text { antebrazo + manos, o mano (según } \\
\text { el hablante una u otra acepción) } \\
\text {-Pata (animales) }\end{array}$ & $\begin{array}{l}\text { MOR } \\
\text { ¿FUN? }\end{array}$ \\
\hline$c h^{\prime} u(\mathrm{~s}), c^{\prime} u l(\mathrm{pl})$ & Estolón & Se registró para Bromeliaceae terrestres. & -Asta, cuerno & $\begin{array}{l}\text { MOR } \\
\text { ¿POS? }\end{array}$ \\
\hline $\begin{array}{l}\text { Ihe'yo (s), Ihe'yos } \\
\text { (pl) } \\
\text { FIG. 3F }\end{array}$ & Estolón; Cogollo & $\begin{array}{l}\text { En el caso de estolones en general refiere a la parte más apical. } \\
\text { Se registró solo para unas pocas especies, como el cogollo de la } \\
\text { palma (jwitsukw, Copernicia alba), la parte interna de la roseta } \\
\text { basal y estolones de Bromeliaceae terrestres. }\end{array}$ & & \\
\hline pose $(\mathrm{s})$, posey $(\mathrm{pl})$ & Estigmas & $\begin{array}{l}\text { Se registró entre algunos entrevistados para las barbas del } \\
\text { choclo (siputkay o ijpat, Zea mays). Siputkay-le-posey / ljpat-le- } \\
\text { posey. Otros les Ilaman ts'iley. }\end{array}$ & $\begin{array}{l}\text {-Barba, bigote (humanos y otros } \\
\text { animales) }\end{array}$ & MOR \\
\hline $\begin{array}{l}\text { jwi'yu } \\
\text { FIG. } 3 E\end{array}$ & Pelos seminales & $\begin{array}{l}\text { Registrado específicamente para los pelos seminales del } \\
\text { 'yuchán', tsem/hokw (Ceiba chodatii), a los que encuentran } \\
\text { similares al 'algodón', que lleva ese nombre, y que en términos } \\
\text { botánicos son también pelos seminales. Quienes usan este } \\
\text { término lo diferencian de los pelos seminales de apocináceas } \\
\text { asclepiadoideas, por ejemplo, diciendo que las últimas son más } \\
\text { semejantes a fibras por su disposición y las denominan ts'iley. }\end{array}$ & & \\
\hline $\begin{array}{l}t^{\prime} a k \\
\text { FIG. 3A }\end{array}$ & $\begin{array}{l}\text { Pedicelo; Pedúnculo; } \\
\text { Pecíolo }\end{array}$ & & $\begin{array}{l}\text {-Manija } \\
\text {-Soga }\end{array}$ & $\begin{array}{l}\text { MOR } \\
\text { FUN }\end{array}$ \\
\hline $\begin{array}{l}\text { p'ot } \\
\text { FIG. 3C }\end{array}$ & Endocarpo & $\begin{array}{l}\text { Literalmente significa 'tapa de la flor'. Se utiliza ocasionalmente } \\
\text { para referirse al endocarpo de ciertas Apocynaceae } \\
\text { asclepiadoideas (p.ej. Marsdenia castillonii), ya que se concibe } \\
\text { que adentro, al quitarlo, se encuentra la flor (conjunto de pelos } \\
\text { seminales). }\end{array}$ & -Tapa & $\begin{array}{l}\text { MOR } \\
\text { FUN }\end{array}$ \\
\hline $\begin{array}{l}\text { jwinchu }(\mathrm{s}), \\
\text { jwinchus (pl) }\end{array}$ & Bráctea & $\begin{array}{l}\text { Se emplea en casos en que las brácteas tengan apariencia } \\
\text { escamosa (p.ej. brácteas de la inflorescencia o de las flores de } \\
\text { ciertas Bromeliaceae terrestres). }\end{array}$ & -Escama (de pez) & MOR \\
\hline ts'ile (s), ts'iley (pl) & $\begin{array}{l}\text { Fibras foliares; Fibras } \\
\text { liberianas; Estigmas }\end{array}$ & $\begin{array}{l}\text { En general se emplea el término en plural. Ejemplos: fibras } \\
\text { foliares de Bromeliaceae textiles (Bromelia spp.), fibras liberianas } \\
\text { de yuchán (Ceiba chodatii), estigmas de maíz (Zea mays). }\end{array}$ & & \\
\hline $\begin{array}{l}\text { kojche (s), kojchey } \\
\text { (pl) }\end{array}$ & Fibras foliares & $\begin{array}{l}\text { Se usa específicamente para fibras foliares de especies textiles } \\
\text { de cháguar (Bromelia spp.). }\end{array}$ & & \\
\hline kotso $(\mathrm{s})$, kotsol (pl) & Agalla & $\begin{array}{l}\text { La expresión habitual es halä-kotso (agalla/nudo del palo/árbol). } \\
\text { Puede tratarse de un tumor que proviene del interior de la } \\
\text { planta, o bien de entomocecidios, como en el caso del 'chañar' } \\
\text { (Geoffroea decorticans). }\end{array}$ & $\begin{array}{l}\text {-Nudo, protuberancia, bulto } \\
\text {-En anatomía humana/animal } \\
\text { varias partes incluyen este término } \\
\text { siempre que sea saliente, } \\
\text { protuberante }\end{array}$ & MOR \\
\hline piinek & Tallos volubles & Registrado para enredaderas de tallos volubles delgados. & & \\
\hline $\begin{array}{l}\text { tälhe }(\mathrm{s}), \text { tälhes o } \\
\text { tälhey }(\mathrm{pl})\end{array}$ & $\begin{array}{l}\text { Brotes (de una planta); } \\
\text { Planta pequeña; Estolón }\end{array}$ & & $\begin{array}{l}\text {-Cosa/parte que crece hacia } \\
\text { afuera, de tälh 'crecer' y el sufijo - } \\
e \text {, direccional 'hacia afuera' }\end{array}$ & $\begin{array}{l}\text { MOR } \\
\text { FUN } \\
\text { ¿POS? }\end{array}$ \\
\hline
\end{tabular}

y que permiten dilucidar los criterios subyacentes en la partonimia y nomenclatura botánica wichí. Los criterios identificados se incluyen también en la Tabla 1. Cuando corresponde, se hace también referencia a las Figuras 2 y 3 , que ilustran las partes y términos mencionados.

Durante el trabajo campo registré 38 términos de partes de plantas. Como puede observarse, en general las partes nombradas son aquellas que todas las plantas tienen, es decir, aquellas que forman la estructura general de una planta según la concepción wichí. Así, más allá de si en todos los casos la concepción vernácula coincide con la botánica académica (p. ej., Iha 'fruto' puede corresponder en ocasiones a un tubérculo o un bulbo, ver Tabla 1), para los wichís casi todas las plantas tienen raíces, tallos, maderas y/o troncos (en el caso de las leñosas), ramas, hojas, flores, frutos, semillas, exudados (savia, resina, látex, mucílago), brotes (plantas hijas) y polen. También todas tienen ciertas partes de sus partes: cáscaras o cortezas, partes internas o 'relleno' (pulpa, albura), el centro o medio (duramen, semillas, médula), copas (en el caso de los árboles o arbustos), agallas o protuberancias y un inicio y un final en cierta estructura. Podríamos decir que los lexemas empleados para todas ellas son en general inconfundibles y únicos, repitiéndose en los distintos dialectos hablados en la zona. La excepción la hace el duramen o médula de tallos, para la cual registré cuatro términos diferentes, que varía según el hablante: chulak, chowej, Ihich'u, t'otle. Otras partes son propias de algunas clases de plantas, pero son igualmente muy comunes: espinas o aguijones, gloquidios, fibras (foliares o liberianas), y sus nombres son también únicos en la zona. Vale la aclaración de que a las fibras en general se las denomina ts'iley, siendo el término kojchey empleado específicamente para referirse a las fibras foliares textiles de cháguar (Bromelia urbaniana o B. hieronymi). Incluso la gente sostiene que no hace falta especificar que se trata de fibras de cháguar si se emplea ese término, porque sería redundante (Suárez y Montani, 2010).

Solamente unos pocos términos fueron mencionados por muy pocos entrevistados y en forma aislada, y todos ellos son en realidad alternativas a otros términos que también pueden aplicarse a las partes referidas, pero 

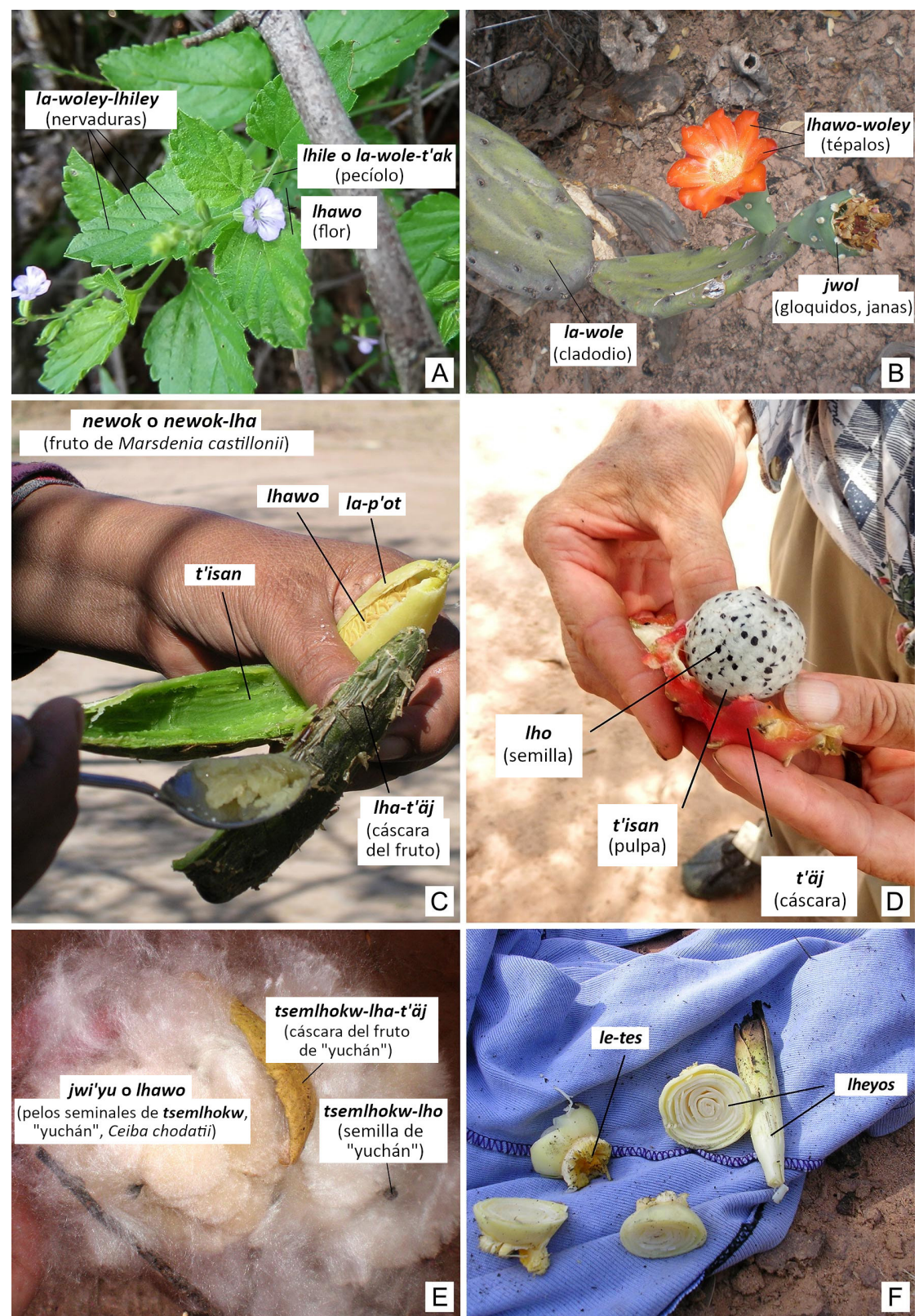

Figura 3. Fotos y nombres wichís de algunas partes de las plantas. A) Pecíolo, nervaduras y flor en planta herbácea. B) Cladodios (artejos), gloquidios (janas) y tépalos en cactus. C) Fruto de la enredadera Marsdenia castillonii y sus partes. D) Partes de un fruto de cactus (Harrisia bonplandii). E) Partes del fruto de 'yuchán', Ceiba chodatii. F) Parte interna de rosetas basales de 'cháguar' (Bromelia hieronymi), tras pelar las bases foliares externas. Los cuatro pedazos de la izquierda están cortados transversalmente para quitar la porción quemada de arriba, tras cocinar las rosetas a fuego directo.

Figure 3. Photos and Wichí names of some plant parts. A) Petiole, ribs and flower in a herbaceous plant. B) Cladode, glochids and tepals in a cactus. C) Fruit of Marsdenia castillonii and its parts. D) Parts of a cactus fruit (Harrisia bonplandii). E) Parts of the fruit of 'yuchán', Ceiba chodatii. F) Internal part of basal rosettes of 'cháguar' (Bromelia hieronymi), after peeling external foliar leaves. The four pieces on the left are transversally cut to remove the upper burnt part, after direct fire cooking of the rosettes. que fueron elegidos para ciertos casos particulares por su semejanza morfológica con partes de humanos/ animales o cosas, según ellos mismos explicaron; ellos son jwinchu, t'ak, p'ot, tsotey, kweyey, posey, jwi'yu. Partes usualmente muy pequeñas, como foliolos, foliolulos, raquis o nervaduras de hojas (Figuras 2B, 3A) no son usualmente nombradas salvo que especialmente se pregunte por ello. Los estambres y gineceo (ovario, estilo, estigma) de las flores, aún aquellos que a ojo desnudo son visibles y conspicuos, no se nombran, con excepción de los estigmas de maíz, que algunos entrevistados llaman posey por encontrarlos semejantes a barbas y otros llaman ts'iley por asemejarse a fibras. Aunque excede los objetivos de este estudio, comento que indagué durante la investigación sobre la ontogenia y ciclos de vida, y puedo afirmar que, a pesar de no nombrarlas, para los entrevistados es muy claro el rol de las partes fértiles en la ontogenia de las plantas: todos indican que el polen (mokw) proviene de los estambres de las flores cuando estos son conspicuos, indican que la flor (Ihawo) es la parte de donde surgen el polen, los frutos y las semillas. Quizás es por su no utilidad general que no tienen un nombre propio. Pétalos y sépalos en general no se nombran tampoco, a menos que sean muy aparentes o llamativos y/o útiles, en cuyo caso se los nombra aludiendo en general a su morfología (Tabla 2).

Por otro lado, y en línea con la utilidad de las plantas, para ciertas especies de gran importancia cultural, tanto a nivel práctico como simbólico, hay terminología muy específica. Es el caso, por ejemplo, de las Bromeliaceae textiles y alimenticias (Bromelia serra, B. urbaniana, B. hieronymi), como puede verse en parte en la Tabla 1 (para más detalles, cf. Suárez y Montani, 2010). Aristóbulo Maranta (1987, p. 174) también registró 
terminología especializada para estas especies. Es el caso además de los algarrobos, en especial el jwa'ayukw 'algarrobo blanco' (Prosopis alba). En un trabajo reciente (Herrera Cano y Suárez, 2020) registramos 13 términos y/o descripciones para distintas clases de frutos del algarrobo blanco (jwa'ay 'frutos de jwa'ayukw'): chuhu o chuh(u)laj '¿enrulados?', pitaj (pl. pites) 'largos', alhe-les 'crías de iguana'; alhe-les layumles 'pequeñas crías de iguana', lupen 'delgados', Ihomsaj (pl. lalémses) 'pequeño' o 'pequeño hijo', yätaj 'gordos', wesche 'grandes', ch'enho-käsley 'tripas de quirquincho', jwa'ay-t'äjes 'cáscaras de algarrobas', Tokjwaj-ch'ote-Ihiley 'aros de Tokjwaj' (personaje de la mitología wichí). Esta terminología y clasificación está asociada a las características organolépticas, sobre todo morfológicas, de las variedades de frutos y, además, está vinculada a los fines utilitarios que pueden darse a las distintas clases de frutos (p. ej., algunos sirven para harina, otros para aloja, otros para ambas cosas). Arenas (2003) y Maranta (1987) registraron también algunos de estos nombres, pero no ahondaron en su análisis. Existen asimismo algunas plantas cuyos frutos tienen un nombre específico, más allá de ser Iha 'fruto' (Tabla 2). Todas estas plantas son también de gran valor cultural, en particular alimenticio. El hecho de que las especies de gran relevancia cultural presenten terminología más especializada no es extraño, ya que en las lenguas se lexicaliza lo que se considera importante (Luque Durán, 2001, p. 270). A la inversa, el hallar nombres tan específicos para partes de ciertas plantas es entonces un indicio de la importancia cultural de estas especies.

\section{Los procesos de asignación de nombres a las partes y los conceptos subyacentes}

Maranta (1987) da una explicación concisa pero contundente sobre cómo es el proceso de asignación de nombres a las plantas alimenticias y a sus partes. Sostiene que "el nombre de la especie alimenticia está dirigido al órgano comestible más significativo", y brinda algunos ejemplos, como el de la 'doca' (Morrenia odorata), cuyo fruto comestible se denomina jwalawukw y la planta jwalawukw-Ihile. Coincido

Tabla 2. Plantas que tienen nombres propios de frutos. Se indica la familia y especie botánica académica, el nombre de la especie en el español local (criollo) y en wichí, y el nombre wichí del fruto.

Table 2. Plants with fruits with particular names. Academic botanical family and species, the species name in local Spanish (Criollo) and in Wichi, and the Wichi name of the fruit, are indicated.

\begin{tabular}{|c|c|c|c|c|}
\hline $\begin{array}{l}\text { Familia } \\
\text { botánica }\end{array}$ & Especie botánica & $\begin{array}{l}\text { Nombre } \\
\text { criollo }\end{array}$ & $\begin{array}{l}\text { Nombre } \\
\text { wichí de la } \\
\text { planta }\end{array}$ & $\begin{array}{l}\text { Nombre } \\
\text { wichí del } \\
\text { fruto }\end{array}$ \\
\hline Rhamnaceae & Ziziphus mistol Griseb. & Mistol & Ahäyukw & Ahäyaj \\
\hline Fabaceae & Prosopis ruscifolia Griseb. & Vinal & Atek & Ataj \\
\hline Capparaceae & $\begin{array}{l}\text { Anisocapparis speciosa (Grise } \\
\text { b.) Cornejo \& Iltis }\end{array}$ & Bola verde & Atsukw & Atsaj \\
\hline Fabaceae & $\begin{array}{l}\text { Prosopis elata (Burkart) } \\
\text { Burkart }\end{array}$ & $\begin{array}{l}\text { Algarrobilla } \\
\text {; Guaschín }\end{array}$ & $\begin{array}{l}\text { Chitetek; } \\
\text { Chitetak }\end{array}$ & $\begin{array}{l}\text { Chitetal } \\
\text { chitete }\end{array}$ \\
\hline Cactaceae & Cereus forbesii C. F. Först & Ucle & Chähätukw & Chähät \\
\hline Sapotaceae & $\begin{array}{l}\text { Sideroxylon obtusifolium (Roe } \\
\text { m. \& Schult.) T.D.Penn. }\end{array}$ & Molle & Hiknak & $\begin{array}{l}\text { Hiknayl } \\
\text { hikna }\end{array}$ \\
\hline Fabaceae & Acacia aroma Hook. \& Arn. & Tusca & $\begin{array}{l}\text { Inhatek; } \\
\text { Natek }\end{array}$ & $\begin{array}{l}\text { Inhataj; } \\
\text { Nataj }\end{array}$ \\
\hline Cactaceae & $\begin{array}{l}\text { Stetsonia coryne (Salm-Dyck) } \\
\text { Britton \& Rose }\end{array}$ & Cardón & Istak & Istaj \\
\hline Fabaceae & Prosopis alba Griseb. & $\begin{array}{l}\text { Algarrobo } \\
\text { blanco }\end{array}$ & Jwa'ayukw & $J w a^{\prime} a$ \\
\hline Santalaceae & Acanthosyris falcata Griseb. & Sacha pera & Jwitenukw & Jwiten \\
\hline Fabaceae & $\begin{array}{l}\text { Geoffroea decorticans Hook. } \\
\text { \& Arn. Burkart }\end{array}$ & Chañar & Letsenukw & Letseni \\
\hline Capparaceae & $\begin{array}{l}\text { Cynophalla retusa (Griseb.) } \\
\text { Cornejo \& Iltis }\end{array}$ & $\begin{array}{l}\text { Poroto del } \\
\text { monte }\end{array}$ & Änhyukw & Änhyaj \\
\hline Cactaceae & Opuntia quimilo K. Schum. & Quimil & Tsowayukw & Tsowa \\
\hline Capparaceae & Capparis salicifolia Griseb. & $\begin{array}{l}\text { Sacha } \\
\text { sandia }\end{array}$ & Onhak & Onhay/ onha \\
\hline Fabaceae & Prosopis nigra Hieron. & $\begin{array}{l}\text { Algarrobo } \\
\text { negro }\end{array}$ & Wosochukw & Wosochaj \\
\hline Fabaceae & $\begin{array}{l}\text { Caesalpinia paraguariensis } \\
\text { (Parodi) Burkart }\end{array}$ & Guayacán & Wäch'äyukw & Wäch'ä \\
\hline
\end{tabular}


con Maranta, pero, en base a datos que exceden las alimenticias, encuentro que el nombre propio se asigna a la parte considerada más importante a nivel cultural. Si la parte que se considera más importante es el 'fruto' (Iha), entonces el nombre propio de la planta es el compuesto [nombre propio de ese fruto+/hile]. Por el contrario, si la especie vegetal en cuestión no tiene una parte con relevancia destacada o bien la parte importante son las hojas o el leño en el caso de árboles o arbustos, entonces el nombre propio corresponde a la planta entera (es el fitónimo sensu stricto) y el fruto pasa a nombrarse con el compuesto [fitónimo+lha]. Un ejemplo del primer caso es precisamente el de la citada 'doca', y un ejemplo del segundo es el de hokw 'palo santo' (Bulnesia sarmientoi).

Maranta menciona también que, en algunos casos, existe una raíz lingüística a la cual se agregan distintos sufijos para designar al fruto o a la planta entera; por ejemplo, para 'bola verde' (Anisocapparis speciosa), se denomina atsaj al fruto y atsukw al árbol. Alvarsson (2012, p. 301) sostiene algo parecido: afirma que entre los 'weenhayek (denominación con la que se reconoce a los wichís de Bolivia) el nombramiento y clasificación de los árboles se hace a partir de su fruta, si la hay. Explica entonces que el nombre del árbol se genera agregando un sufijo al nombre de las frutas, y da algunos ejemplos, como el del 'chañar' (Geoffroea decorticans), siendo letseni el nombre del fruto y letsenukw el del árbol. En trabajos previos analicé en parte estas cuestiones (Suárez, 2010, $2011,2014)$ y encontré que existe una marca lingüística en los fitónimos, el sufijo - $V k$ o $-V k w$, que cumple el rol de sufijo derivativo e identifica a plantas leñosas. Algo muy parecido sucede en otras lenguas de la familia lingüística mataguaya, como el maká y el chorote (Messineo y Tacconi, 2010; Scarpa, 2007). Aunque los lingüistas del wichí ya habían identificado formas del sufijo que indico (p. ej., Viñas Urquiza, 1974a; Terraza, 2009), lo presentaban en general como marcador de árboles, no de leñosas en general. Más recientemente, Alvarsson (2012, p. 301) y Nercesian (2014, p. 190) también mencionan un sufijo parecido y lo asocian a árboles. Por otro lado, nuevos resultados arrojan más luz al tema. En la Tabla 2 presento el listado de especies botánicas para las cuales registré nombres específicos de frutos. De 235 especies estudiadas, solamente para 16 encontré nombres de frutos distintivos, i.e. frutos que tienen nombre propio, más allá de ser lhay (frutos) en general.

El análisis de los nombres de frutos y plantas de la Tabla 2 muestra dos cosas. Por un lado, que todos los fitónimos presentan el sufijo derivativo arriba mencionado (-Vk o $-V k w$ ) y son leñosas. Luego, que en casi la mitad de los casos (7/16) el nombre del fruto se forma, al parecer, agregando el sufijo - aj a la misma raíz -en un solo caso se agrega el sufijo - $i$ a la raíz: letseni. En la otra mitad (8/16), el nombre de la planta se deriva del nombre del fruto, que sería en todo caso la raíz. En estos casos, la afirmación de Alvarsson de que el nombre de la planta deriva del nombre del fruto, parece ser correcta. Pero también podría ser correcta la interpretación de Maranta, según la cual los nombres de la planta y de la fruta son derivaciones de una misma raíz con diferentes sufijos, ya que la otra mitad de los datos apoyan esta postura. Me inclino más hacia esta última, porque el sufijo marcador de leñosas se encuentra en muchas más especies que las de este listado (Suárez, 2010, 2014). Por otro lado, en la lengua maká, Messineo y Tacconi (2010) han identificado sufijos $-i,-a X$ y $-a$ ?, que sirven para derivar a partir de los nombres de los árboles los nombres de los frutos. No es arriesgado ver en estos sufijos makás unos cognados de los mencionados sufijos wichís $-i,-a j$ y $-a$. Si así fuera, cinco de los ocho nombres en los que el fitónimo parece derivar del nombre del fruto, serían también nombres generados por derivación a partir de una raíz. Sea como fuere, considero que lo que está sucediendo en estos casos es que la marca lingüística que los frutos de la Tabla 2 llevan en su nombre se aplica específicamente a estos y no a otros por dos motivos fundamentales: a) son frutos de especies leñosas muy habituales y de las más importantes culturalmente por su utilidad y/o su rol simbólico (cf. Suárez, 2014); y b) más allá de la planta entera, estos frutos tienen una relevancia cultural elevada por sí solos, la cual radica básicamente en su rol en el ámbito alimenticio (cf. Alvarsson, 2012; Arenas, 2003; Maranta, 1987; Suárez, 2014). En estos casos, entonces, la utilidad de los frutos es un factor clave en el proceso de asignación de nombres especiales.

En lo que respecta a la forma de nombrar partes vegetales y los conceptos subyacentes, se destaca la concepción vernácula de Iha 'fruto'. Como se menciona en la Tabla 1, Iha nombra tanto frutos como tubérculos, bulbos o raíces engrosadas. En todos los casos, la morfología y la utilidad de estas partes es crucial para ser considerado Iha. Siempre son relativamente engrosadas y/o tienen algún uso, ya sea alimenticio, hidrorreservante, medicinal o mágico. Di algunos ejemplos en trabajos previos (Suárez, 2014, 2019). Ahora bien, esta situación me llevó a indagar sobre la posibilidad de que, en la concepción vernácula, una misma planta pueda tener más de un Iha $\mathrm{y}$, en ese caso, a preguntarme cómo se nombran o distinguen lingüísticamente un Iha del otro, si es que se lo hace. Para el caso de las alimenticias, Maranta (1987, p. 174) detalla la forma en que sus entrevistados distinguen ambos frutos, cuando coexisten: ch'ithan-Ihile es la planta Harrisia bonplandii, ch'ithan-Ihay son los frutos y ch'ithanlhile-Ihay son las raíces comestibles. En mi caso, la mayoría de los entrevistados sostuvieron que por lo general no hay dos Ihay, solo uno, o bien arriba o bien abajo de la tierra. Llegado el caso de que una planta tenga ambos, uno sabe a cuál se hace referencia por el contexto: "es que uno ya sabe si lha está arriba o abajo [de la tierra]". Sólo unos pocos consultados, de los más ancianos y/o montaraces, respondieron tal como lo registró Maranta. Esto se debe a que actualmente 
la mayoría de los entrevistados desconocen la utilidad de algunas partes, sobre todo las subterráneas -o si la conocen no la emplean en la práctica. Muchos desconocen incluso el antiguo uso alimenticio de las raíces tuberosas de la llamada newok 'mandioca del monte' (Marsdenia castillonii), y solo consumen el fruto, por lo que a las primeras las llaman simplemente jwetes 'raíz'. La pérdida de conocimientos sobre las especies del entorno se traduce así en una pérdida del léxico específico.

En cuanto a las demás partes vegetales (hojas, ramas, flores, exudados, agallas, tallos, etc.), los lexemas de la parte aparecen a continuación del nombre de la planta, al igual que ocurre con los frutos que no tienen nombre especial o propio, siguiendo la fórmula [fitónimo + término de la parte]; por ejemplo, para watujw (Albizia inundata): watujw-woley 'hojas de watujw', watujwIhawu 'flores de watujw' y watujw-lachal 'ramas de watujw' (Tabla 1). Lo mismo aplica para los casos detallados en la Tabla 2, con excepción de las semillas, que siempre son referenciadas al fruto. Así, por ejemplo, para Anisocapparis speciosa, se dice atsukw-woley para las hojas y atsukw-lhawu para las flores, pero se dice atsaj-Ihoy para hablar de sus semillas. En los casos de partes específicas de otras partes, como 'cáscaras' o 'cortezas' ( $t$ 'äj), 'pulpa' o 'relleno' ( $t$ 'isan), entre otras, se especifica antes del vocablo de qué parte es la cáscara o pulpa; por ejemplo, atsajlhoy-t'äj, 'cáscara de la semilla de bola verde', atsaj-t'äj, 'cáscara del fruto bola verde', atsaj-t'isan, 'pulpa del fruto bola verde'. Todas estas formas de nombrar a las partes coinciden con lo detallado por Maranta (1987).

Por último, vuelvo a las formas de nombrar partes poco aparentes como los pétalos y sépalos. Lo más habitual es que no se les nombre, o sólo lo hagan motivados por mis preguntas, luego de haber observado sus atributos, su posición en la planta y su relación con las partes aledañas. Tanto a los pétalos y los sépalos como a las brácteas o estípulas, por ejemplo, les aplican el término wole 'hoja', pues por su morfología se asemejan a las hojas. Si las partes además tienen colores vívidos como los que caracterizan a las flores en general, y/o están en o alrededor de las flores o inflorescencias, entonces se las llama, por ejemplo, Ihawu-woley 'hojas de la flor'. En el caso de foliolos o foliolulos y de nervaduras o raquis de las hojas, solo se dice que se denominan, respectivamente, woley 'hojas' y Ihiley 'tallos/ejes', y sólo al preguntar por ellos en específico. En la Figura 2 puede verse que se llama wole tanto a la hoja entera, como a la lámina y a foliolos y foliolulos, y que para diferenciar alguno de ellos de una parte mayor se los denomina wole-jwaj 'hoja pequeña'. Lo mismo sucede con el tallo que porta la hoja, el pecíolo, raquis y nervaduras, a todos se los llama Ihile. Sin ahondar aquí en las concepciones vernáculas sobre la ontogenia y otros aspectos concernientes a la morfología vegetal o a la arquitectura vegetal, que será materia de análisis a futuro, menciono que, tal como para la morfología vegetal de la botánica académica se concibe que las plantas son organismos modulares que se desarrollan por repetición de entidades botánicas elementales (Barthélémy y Caraglio, 2007; Perreta y Vegetti, 2005), aunque no necesariamente por los mismo motivos o de idéntica manera, en el caso wichí subyace también la idea de repetición o reiteración durante el desarrollo ontogénico. Esta idea subyacente de desarrollo por repetición y el conocimiento del patrón estructural permiten a la gente nombrar rápidamente partes a las que nunca antes les prestó atención o no tuvo la necesidad de nombrar.

\section{Criterios detrás de la nomenclatura de partes vegetales}

De los 38 términos para partes vegetales registrados, 25 son homónimos de partes anatómicas de humanos/ animales y/o de conceptos de otros campos semánticos, por ejemplo, de posiciones (Tabla 1). Los criterios que están por detrás de esas analogías son morfológicos, funcionales y/o posicionales. Al observarlos en conjunto se desprende que el criterio morfológico es, aunque no por mucho, el que más presente está (17/25, frente a $14 / 25$ el posicional y 12/25 el funcional). Sin embargo, las analogías están mayormente motivadas por una combinación de criterios (14/25, frente a 5/25 en que solo aparece el morfológico, 5/25 el posicional y 1/25 el funcional). En su libro sobre la cultura wichí, Montani (2017) hace reiteradas menciones a las analogías de nombres entre partes del cuerpo humano, animal, vegetal y artefactual. Explica, por un lado, que la transferencia metafórica o metonímica de nombres de partes humanas, animales o vegetales al campo semántico de los artefactos se apoya en semejanzas funcionales, morfológicas y/o posicionales, pero además se combina con explicaciones míticas y/o simbolismos que dotan de animacidad a ciertos objetos (Montani, 2017, pp. 522-524). También en el ámbito vegetal se observan todos estos tipos de motivaciones (Tabla 1). Aquí no voy a ahondar en los mitos y simbolismos que puedan estar motivando los nombres de partes vegetales homónimos de partes humanas/ animales, pero es muy probable que los wichís también estén dotando de animacidad a los vegetales, al menos a algunos, definida como atributos de intención, voluntad y conciencia. Al menos eso es lo que hemos encontrado que sucede con las Bromeliaceae (Suárez y Montani, 2010). Así, los resultados de este estudio se suman a otros que muestran que las motivaciones subyacentes al nombrar entidades se asocian con lo perceptual, lo funcional, lo posicional y/o lo simbólico (p. ej., Ellen, 2006; Kujawska et al., 2017; Montani, 2017; Poncet et al., 2015); si bien quedará para futuro evaluar en función de qué factores (p.ej., edad, género) varían los nombres y clasificaciones, queda claro por el momento que es la conjugación de criterios y factores, en general, la que se plasma en la asignación de nombres y en la clasificación de entidades 
vinculadas a la naturaleza.

Montani explicita además que entre una posible interpretación fitomórfica del cuerpo humano/animal por parte de los wichís, como pareciera ser la de Braunstein (1974), y una interpretación antropomorfizada de la corporalidad animal y vegetal, como la que propuso de los Ríos (1976), se inclina por esta última, apoyándose para ello en las teorías de la corporización (Cuenca y Hilferty, 1999; Key, 1990) y de la gramaticalización (Heine, 1997) de la lingüística cognitiva². Además de coincidir con sus fundamentos, mis datos parecen estar en línea con su postura, ya que las explicaciones que surgen de los propios entrevistados al indagar sobre los motivos detrás de los nombres de partes homónimas con partes del cuerpo animal/humano remiten a las semejanzas morfológicos, posicionales y/o funcionales con ellas, siendo éstas las tomadas como prototípicas y de referencia. Esto es sobre todo evidente en el caso de los nombres de partes provistos solo por algunos entrevistados (Tabla 1): aún cuando estas partes pueden tener otros nombres propios, estas personas le atribuyen además estos nombres por asemejarse a partes humanas/ animales, por ejemplo, kweyey 'brazos', para referirse a ramas de Jatropha spp. Además, la transferencia metafórica desde el cuerpo humano/animal a las plantas y la polisemia que de ello resulta podrían ser un reflejo de una forma particular de vinculación e identificación de los humanos con los seres del entorno, que siguiendo a Descola (2012) podríamos llamar "animista".

Para concluir, me pregunto qué sucede con los once nombres de partes que no son polisémicos, que no son homónimos de otros conceptos: jwetes 'raíz', Iha 'fruto', Ihacha 'rama', halä 'madera/palo/tronco', ch'ithan 'espina', jwo 'gloquidio', Ihe'yo 'estolón/brote/cogollo', Ihits'i 'exudados', Ihawu 'flor', ts'iley y kojchey 'fibras'. ¿Quizá son estas partes las que para los wichís distinguen o caracterizan a las plantas como tales?

\section{Consideraciones finales}

En este artículo describí y analicé 38 términos wichís que aluden a partes vegetales, con el fin de comprender algunos aspectos de la morfología botánica desde la perspectiva nativa y contribuir a conocer la etnobiología, en particular aspectos etnoclasificatorios y perceptuales, de este pueblo indígena. En particular, y para contribuir eventualmente con la educación intercultural bilingüe formal y no-formal, especifiqué las correspondencias

\footnotetext{
2 "La teoría de la corporización sostiene que existe una tendencia translingüística a que el léxico de las lenguas se genere extendiendo nociones concretas relacionadas con el cuerpo humano para conceptualizar realidades más alejadas y amplias, incluyendo animales, vegetales y artefactos (Cuenca y Hilferty, 1999; Key, 1990). Asimismo, la teoría de la gramaticalización de Heine (1997, pp. 131146) da cuenta del siguiente proceso de transferencia metafórica unidireccional: elementos animados o inanimados > partes animadas de un todo > partes inanimadas de un todo" (Montani, 2017, p. 524).
}

botánicas exactas según mis resultados y describí los procedimientos que siguen los wichís para la asignación de nombres a las partes vegetales.

Encontré que algunos de los términos son homónimos de partes del cuerpo de humanos y animales o de conceptos abstractos, mientras otros remiten a partes que serían las distintivas de lo vegetal según su concepción. Algunas partes, aquellas no muy aparentes y/o sin utilidad destacada, no se nombran salvo necesidad específica, para lo cual se recurre entonces a construcciones motivadas por aspectos morfológicos o posicionales mayormente. Además, propuse la existencia de algunos sufijos que serían marcador de frutos, pero no de cualquier fruto, sino de aquellos con gran relevancia cultural, especialmente utilitaria. En esta línea, las plantas con destacada relevancia cultural suelen tener un léxico más especializado para nombrar sus partes, por lo que el análisis terminológico resulta una vía útil para identificar especies y recursos de importancia local.Por otro lado, sostuve que no existe a mi criterio un término vernáculo que pueda traducirse como 'planta' en su acepción de conjunto de especies vegetales, es decir, que si para los wichís existe una categoría de planta, ella es innombrada, sin etiqueta; sin embargo, el término /hile parecería estar adquiriendo este significado o siendo usado en este sentido en el nuevo contexto sociocultural. En cuanto al proceso de asignación de nombres a las partes vegetales, encontré una idea subyacente de repetición o reiteración basada en lo que se concibe como la estructura basal o patrón en el desarrollo vegetal. Son criterios morfológicos, funcionales, posicionales y simbólicos los que, entrelazados e integrados, motivan la asignación de nombres a las partes de las plantas, aunque resta para el futuro indagar sobre los factores (como la edad o el género) que juegan un rol en los criterios que se emplean al nombrar. Por último, un hallazgo interesante y de relevancia a distintas disciplinas vinculadas a la diversidad y conservación biológica y cultural fue que la nomenclatura botánica vernácula refleja en ciertos casos la pérdida de saberes y/o prácticas sobre la utilidad de ciertas especies silvestres, por lo que su estudio puede contribuir a la comprensión de los efectos y causas de los cambios socioambientales a través del tiempo.

Buenos Aires, 4 de marzo de 2020.

\section{Agradecimientos}

Como siempre, principalmente a mis amigos y colaboradores wichís, a quienes pertenecen estos conocimientos y cuyas luchas espero aportar con esta contribución. A mi amiga del alma, Verónica Joly, por los dibujos, y a Mariana Valente por su ayuda en la confección en las láminas. A Rodrigo Montani, Zelda Franceschi y dos evaluadores anónimos de la revista, por sus sugerencias y aportes constructivos. Este trabajo 
se financió parcialmente con subsidios otorgados por la Agencia Nacional de Promociones Científicas y Técnicas, Argentina [PICT-2013-2190; PICT-20131633] y la Universidad de Buenos Aires, Argentina [UBACYT-2016-20020150200191BA; UBACYT-201820020170200233BA].

\section{Bibliografía}

Alvarsson, J.A. (2012). Etnografía 'weenhayek, volumen 6. El individuo y el ambiente. Cosmología, etnobiología y etnomedicina. Uppsala: Dissertations and Documents in Cultural Anthropolgy $N^{\circ} 11$.

Arenas, P. (2003). Etnografía y Alimentación entre los Toba-Nachilamole\#ek y Wichi-Lhuku'tas del Chaco Central (Argentina). Buenos Aires: Pastor Arenas Ed.

Arenas, P. y Martínez, G. (2012). Estudio etnobotánico en regiones áridas y semiáridas en Argentina y zonas limítrofes. Experiencias y reflexiones metodológicas de un grupo de investigación. En Arenas P. (Ed.). Etnobotánica en Zonas Áridas y Semiáridas del cono sur de Sudamérica, Buenos Aires: CEFYBO-CONICET, pp. 11-43.

Berlin, B. (1992). Ethnobiological classification: Principles of categorisation of plants and animals in traditional societies. Princeton: Princeton University Press.

Barthélémy, D. y Y. Caraglio. (2007). Plant Architecture: A Dynamic, Multilevel and Comprehensive Approach to Plant Form, Structure and Ontogeny. Annals of Botany 99(3), 375-407.

Blount, B. G. (2011). A history of cognitive anthropology. En: D. B. Kronenfeld, G. Bennardo, V. C. de Munck y M. D. Fischer (eds.), A Companion to Cognitive Anthropology, (pp. 11-29). Blackwell Publishing Ltd.

Braunstein, J. A. (1974). Dominios y jerarquías en la cosmovisión de los matacos tewokleley. Scripta Ethnologica 2(2), 7-30.

Brown, C. H. (1995). Lexical acculturation and ethnobiology: utilitarianism versus intellectualism. Journal of Linguistic Anthropology 5(1), 51-64.

Dwyer, P.D. (2005). Ethnoclassification, ethnoecology and the imagination. Journal de la Société des Océanistes 120-121, 10-25.

Cardona, G. R. (1994). Los lenguajes del saber. Barcelona: Gedisa.

Cuenca, M. J. y Hilferty, J. (1999). Introducción a la lingüística cognitiva. Barcelona: Ariel.

Dell'Arciprete, A. y J. Braunstein. (2006). Fraseario y léxico anatómico para el contacto de los efectores del sistema de salud con indígenas pilagá y wichízluqutás en el centro-oeste de la provincia de Formosa. Las Lomitas: Centro del Hombre Antiguo Chaqueño.

De los Ríos, M. A. (1976). Notas en torno a la nomenclatura del cuerpo (etnia mataco). Buenos Aires: Tekné.

Descola, P. (2012). Más allá de naturaleza y cultura. Buenos Aires: Amorrortu.

Ellen, R. (2006). The categorical impulse: essays in the anthropology of classifying behaviour. Oxford: Berghahn.

Ellen, R. (2018). Ethnobiology. En: H. Callan (ed.)., The International Encyclopedia of Anthropology. New York: John Wiley \& Sons, Ltd.

Friedberg, C. (1990). Le savoir botanique des Bunaq. Percevoir et classer dans le Haut Lamaknen (Timor, Indonésie). Paris: Éditions du Meséum.

Golluscio, L. A., Vidal, A., 2010. Recorrido sobre las lenguas del Chaco y los aportes a la investigación lingüística, En: Golluscio, L., Vidal, A. (Eds.), Les Langues du Chaco. Structure de la phrase simple et de la phrase complexe. Amerindia 33/34, 3-40.

Hansen, M. C., Potapov, P. V., Moore, R.,... et al. (2013). High-resolution global maps of 21 st-century forest cover change. Science 342, 850-853.

Heine, B. (1997). Cognitive Fundations of Grammar. Nueva York: Oxford University Press.

Herrera Cano, A. N. y M. E. Suárez. (2020) Ethnobiology of algarroba beer, the ancestral fermented beverage of the Wichí people of the Gran Chaco I: a detailed recipe and a thorough analysis of the process. Journal of Ethnic Foods (2020) 7:4.

Hunn, E. (1982). The utilitarian factor in folk biological classification. American Anthropologist 84(4), 830-847.

Hunt, Richard J. (1936): Mataco-English and EnglishMataco Dictionary (with grammatical notes). Ethnological Studies, N 5. Sweden: Gothenburg.

Key, M. R. (1990). Semantic Structures as Seen in Comparative Linguistics. Scripta Ethnologica, Supplementa 10, 131-136. 
Kujawska, M., Jiménez-Escobar, D., Nolan, J. M. y Arias-Mutis, D. (2017). Cognition, culture and utility: plant classification by Paraguayan immigrant farmers in Misiones, Argentina. Journal of Ethnobiology and Ethnomedicine (2017) 13: 42.

Leake, A. (Coord.). (2010). Los pueblos indígenas cazadores-recolectores del Chaco Salteño: población, economía y tierras. Salta: ASOCIANA-INAI-UNSA.

Ludwig, D. (2018). Does Cognition Still Matter in Ethnobiology? Ethnobiology Letters 9(2), 269-275.

Luque Durán, J. de D. (2001). Aspectos universales y particulares del léxico de las lenguas del mundo. Granada: Método.

Lunt, R. (2016). Diccionario de la lengua wichí. Wichíespañol. Buenos Aires: Sociedad Bíblica Argentina.

Maranta, A. A. (1987). Los recursos vegetales alimenticios de la etnia mataco del Chaco centro occidental. Parodiana 5: 161-237.

Medin, D. L., Lynch, E. B., Coley, J. D. (1997). Categorization and reasoning among tree experts: do all roads lead to Rome? Cognitive Psychology 32 (1), 49-96.

Messineo, C. y Tacconi, T. (2010). Recursos de formación del léxico en maká (mataguayo): zoonimia y fitonimia. En: C. Messineo, G. F. Scarpa y F. Tola (comp.), Léxico y categorización etnobiológica en grupos indígenas del Gran Chaco, (pp. 83-116). Santa Rosa: Inst. de Lingüística, Fac. de Ciencias Humanas, Universidad Nacional de La Pampa.

Montani, R. (2017). El mundo de las cosas entre los wichís del Gran Chaco. Un estudio etnolingüístico. Scripta autochtona 17. Cochabamba: Instituto Latinoamericano de Misionología, Itinerarios Editorial, Centro de Investigaciones Históricas y Antropológicas.

Montes-Rodríguez, M. E. (2001). Los nombres de las plantas, sus partes y sus espacios de crecimiento. Aproximación etnolingiística a partir de datos de la lengua tikuna, Amazonia colombiana. En: C. E. Franky y C. G. Zárate (eds.), Imanimundo, estudios en la Amazonia colombiana, (pp. 523-558). Bogotá: Universidad Nacional de Colombia.

Nercesian, V. (2014). Wichi Ihomtes. Estudio de la gramática y la interacción fonología-morfologíasintaxis-semántica. Muenchen: LINCOM GmbH.

Palmer, J. (2005). La buena voluntad wichí: una espiritualidad indígena. Las Lomitas: Grupo de
Trabajo Ruta 81.

Perreta, M. G. y A. C. Vegetti. (2005). Patrones estructurales en las plantas vasculares: una revisión. Gayana Botanica 62(1): 9-19.

Poncet, A., Vogl, C. R. y Weckerle, C. S. (2015). Folkbotanical classification: morphological, ecological and utilitarian characterization of plants in the Napf region, Switzerland. Journal of Ethnobiology and Ethnomedicine (2015) 11:13.

Ross, N. y W. B. Hertzog. (2018). Ethnobiology and Cognition. En: H. Callan (ed.)., The International Encyclopedia of Anthropology. New York: John Wiley \& Sons, Ltd.

Scarpa, G. F. (2007). Hacia una etnotaxonomía vegetal chorote I: fitonimia, sistema nomenclatural y comparación dialectal. Suplemento Antropológico 42(1): 81-119.

Schmidt, M. A. (2011). Educación, Interculturalidad y Territorio en Salta. Revista Latinoamericana PACARINA de Ciencias Sociales y Humanidades 1, 63-83.

Schmidt, M. A. y A. C. Hecht. (2015). Cartografías de la educación intercultural. Acerca de los maestros indígenas en Argentina. Temas de Educación 21(2), 295-310.

Suárez, M. E. (2010). Fitonimia wichí de especies arbóreas y arbustivas del Chaco Semiárido salteño. En: C. Messineo, G. F. Scarpa y F. Tola (comp.), Léxico y categorización etnobiológica en grupos indígenas del Gran Chaco, (pp. 199-224). Santa Rosa: Instituto de Lingüística, Facultad de Ciencias Humanas, Universidad Nacional de La Pampa.

Suárez, M.E. (2011). Fitonimia wichí de plantas herbáceas y bejucos. Bonplandia 20(2): 185-202.

Suárez, M. E. (2012). Espíritus vinculados con el bosque y sus plantas en el mundo de los wichís del Chaco Semiárido salteño, Argentina. En: P. Arenas (ed.), Etnobotánica en zonas áridas y semiáridas del Cono Sur de Sudamérica, (pp. 145-177). Buenos Aires: CEFYBO-CONICET.

Suárez, M. E. (2014). Etnobotánica wichí del bosque xerófito en el Chaco Semiárido salteño. Buenos Aires: Autores de Argentina.

Suárez, M. E. (2019). Medicines in the forest: wild plants in the pharmacopeia of the Wichí people of the Gran Chaco region. Journal of Ethnopharmacology 231: 525-544 
Suárez, M. E. y Montani, R. M. (2010). Vernacular knowledge of Bromeliaceae species among the Wichí people of the Gran Chaco, Argentina. Journal of Ethnobiology 30(2): 269-292.

Terraza, J. (2009). Grammaire du wichí: phonologie et morphosyntaxe. Tesis de doctorado, Universidad de Québec à Montréal.

Tovar, A. 1981. Relatos y diálogos de los matacos seguidos de una gramática de su lengua. Ediciones Cultura Hispánica del Instituto de Cooperación Iberoamericana, Madrid.

Viñas Urquiza, M. T. (1974a). Lengua mataca. Vol.
1. Buenos Aires: Archivo de lenguas precolombinas, Facultad de Filosofía y Letras, Centro de Estudios Lingüísticos.

Viñas Urquiza, M. T. (1974b). Lengua mataca. Vol. 2. Buenos Aires: Archivo de lenguas precolombinas, Facultad de Filosofía y Letras, Centro de Estudios Lingüísticos.

Wallis, C. (2010). Discurso y realidad de la ElB en comunidades wichí del Pilcomayo, Salta: ¿Es factible la interculturalidad en la escuela públlca?. En: S. M. Hirsch y A. Serrudo, La Educación Intercultural Bilingüe en la Argentina: identidades, lenguas y protagonistas, (pp. 149-173). Buenos Aires: Noveduc. 